\title{
Estimation of dilution in buoyant effluents discharged into a current
}

\section{J. J. Sharp and E. Moore}

\section{Mr P. J. D. Neville-Jones, Binnie and Partners}

Professor Sharp's review of initial dilution prediction methods is most interesting. The fact that so many theories fit the various data is testimony to the wide scatter in measured dilutions. While leading the WRC Engineering Sea Outfall Research Project we undertook a similar study of the American and UK prediction methods. The study showed that by applying the fundamental equations of motions to the UK field data, more general and simpler formulae for the prediction of initial dilution could be derived. ${ }^{28}$

51. The new formulae are not only more logical than the empirical formula but give a better fit to the various data sets.

52. The results were compared with the US Environmental Protection Agency's mathematical models ${ }^{29}$ and available laboratory data. The EPA's OuTPLUME model was found to be most appropriate to UK coastal conditions; however, the application of a sophisticated mathematical model is difficult to justify when the scatter of the field data is considered.

53. The findings of this study have been published in the Proceedings, ${ }^{30}$ but may be summarized as follows.

(a) In typical UK coastal conditions, the initial dilution at slack tide falls to a value around three times greater than that predicted by still water formula. $^{4}$

(b) The Agg equations ${ }^{26}$ give reasonable results for typical outfall situations; although for large depth to port diameter ratios, the predictions may be three times too low.

(c) The HR equations ${ }^{22}$ based on laboratory experiments give high dilutions due to the close proximity of the port to the flume bed, and some consequent bed attachment effects.

(d) The Clacton field work ${ }^{21}$ suggests that time averaged dilutions are around 3.4 times the instantaneous minimum dilution for significant ambient current speeds.

(e) The Hastings work provides a valuable basis to estimate the probability of occurrence of particular values of initial dilution. ${ }^{23}$

\section{References}

28. LEE J. H. W. et al. Initial dilution of buoyant sewage discharges in moving water. Water Research Centre, Swindon, 1987, Technical Report.

29. SOLDATE A. M. et al. Initial mixing characteristics of municipal ocean discharges. US Environmental Protection Agency, Corvallis Environmental Research Laboratory, Oregon, 1983.

30. LeE J. H. W. and Neville-Jones P. Sea outfall design-prediction of initial dilution. Proc. Instn Civ. Engrs, Part 1, 1987, 82, Oct., 981-994. 